\title{
Nos Labirintos da Política de Cotas para Negros no Ensino Superior
}

ANDRÉ AUGUSTO BRANDÃO*

MANI TEBET A. DE MARINS**

\author{
BOWEN, William G.; BOK, Derek. \\ O Curso do Rio: Um estudo sobre \\ ação afirmativa no acesso à universidade. \\ Rio de Janeiro: Garamond, 2004.
}

Se a questão da política de cotas para negros pode ser representada como um traiçoeiro labirinto, o livro de Bowen e Bok aparece como um providencial fio de Ariadne. $O$ Curso do Rio foi publicado nos Estados Unidos em 1998, momento em que proliferavam ações judiciais e debates mediáticos contrários ao uso da raça como critério de seleção acadêmica para o ensino superior. Em nosso caso, a publicação em 2004 também se fez oportuna, pois estávamos iniciando, sob cerrado fogo crítico, as primeiras e ainda tímidas iniciativas nessa direção.

Tanto lá no coração da América do Norte, quanto aqui no Brasil, vários discursos contrários ou favoráveis a tal forma de seleção acadêmica são veiculados sem, no entanto, passarem por qualquer teste empírico. O livro se propõe a preencher essa lacuna no que tange à realidade dos Estados Unidos. Trata-se de um estudo pioneiro no campo e que não se resguarda em qualquer posição de neutralidade. Ao contrário disto, posiciona-se claramente a favor de tais políticas, e o faz somente porque se funda sobre demonstrações estatísticas precisas.

Para tanto, os autores lançam mão do estudo quantitativo de um banco de dados de grandes proporções denominado "graduação e experiência posterior", que cobre 28 faculdades e universidades norte-americanas com alta seletividade em suas políticas de admissão. Foram investigados aproximadamente 80.000 alunos que haviam se matriculado nessas instituições nos outonos de 1959,1976 e 1989 . As notas de graduação de todos foram compiladas e grande parte dos ex-alunos respondeu a um extenso questionário acerca de sua vida na graduação e após esta, cujas variáveis principais são tratadas de forma exaustiva. Apesar de outras minorias (asiático-americanos e latinos) serem citadas no decorrer das muitas páginas do estudo, o livro se concentra na comparação entre brancos e negros dos sexos feminino e masculino. 
O capítulo inicial descreve a história que cerca as primeiras iniciativas de "admissão sensível à raça" em instituições de ensino superior norteamericanas. O pressuposto fundamental para a existência dessa diretriz seria a manutenção de uma nítida desigualdade social por raça nos EUA, que atrapalharia as relações entre brancos e negros no sentido da produção de uma sociedade capaz de integrar seus vários segmentos.

O capítulo dois qualifica o que significaria a não-adoção de políticas de admissão sensíveis à raça. Nas instituições norte-americanas mais seletivas, o percentual de alunos negros cairia de $7 \%$ para $2 \%$ do total dos estudantes. $\mathrm{Na}$ mesma direção vemos, através de simulações estatísticas, que uma política sensível somente à classe e color blind diminuiria a presença de alunos negros com excelência acadêmica nas universidades. Isto porque, no caso norteamericano, existiria um estoque muito maior de pobres brancos do que de pobres negros capazes de pleitear a admissão no ensino superior. Além disso, em geral, mesmo entre alunos igualmente pobres, as notas correspondentes ao ensino médio dos negros tendem a ser menores que a dos brancos. Por fim, a obra aponta que uma política de admissão que se preocupasse somente com os alunos mais pobres teria um custo financeiro excessivamente elevado para as instituições seletivas.

Entre os capítulos três e oito se encontra o núcleo mais fundamental do estudo. Neles, usando como escopo o banco de dados e explorando suas variáveis na relação com o desempenho acadêmico na graduação, e antes desta, o livro vai desmontando passo a passo os argumentos até então amplamente difundidos na mídia e imiscuídos no senso comum, utilizados pelos que fazem oposição à consideração da raça como um fator para a admissão no ensino superior.

Os argumentos contrários à "admissão sensível à raça" são tangenciais àqueles mobilizados no Brasil - seja pela mídia ou mesmo por alguns representantes do meio acadêmico. Em resumo, os que repudiam tais políticas propugnam que estas: a) seriam um verdadeiro simulacro para os negros, pois os jogariam em instituições para as quais não estariam intelectualmente preparados e os fariam competir cotidianamente com alunos brancos, cujas notas médias os deixariam em situação de inferioridade (principalmente por conta da forma de admissão da qual teriam se beneficiado); e b) agravariam tensões entre brancos e negros, tanto nos campi quanto na sociedade em geral.

O estudo quantitativo produzido mostra, no entanto, que os negros que foram admitidos nas instituições mais seletivas tiveram sucesso indiscutível, 
tanto no que tange ao percentual de diplomados, quanto no que diz respeito ao acesso à pós-graduação e às profissões liberais de prestígio. Esse "sucesso" é equiparável ao dos alunos brancos das mesmas instituições e superior ao dos alunos negros que cursaram universidades não-seletivas.

Chama atenção, contudo, que o "sucesso" dos alunos negros se fez apesar de, na média, estes apresentarem na graduação notas inferiores àquelas dos brancos. De fato, mesmo os negros com notas anteriores equivalentes à média dos brancos apresentam performances inferiores a estes na graduação. Trata-se, aqui, do que os autores denominam como "subaproveitamento".

O livro explica a configuração através da hipótese de que os alunos negros enfrentarem uma universidade que por gerações foi hostil ao seu grupo de origem deve impactar de alguma forma - ainda que em grau não quantificável - suas energias emocionais e suas possibilidades de crescimento acadêmico.

Mas tal situação não é irreversível. Vemos através de exemplos precisos que programas institucionais específicos voltados para orientação e apoio aos estudantes oriundos de minorias conseguem mudar essa realidade, possibilitando ganhos expressivos no aproveitamento discente. E isto, mesmo nos mais seletivos espaços de formação.

Em relação à renda auferida no mercado de trabalho pelos negros formados em instituições seletivas, o livro aponta que esta ultrapassa a renda dos negros oriundos de instituições não-seletivas. No entanto, a renda é inferior a dos brancos, ainda que dentro da mesma área de qualificação ou do mesmo patamar de notas na graduação, o que se deve à resistência do racismo que opera no seio da sociedade.

A "participação cívica" tão valorizada pelos norte-americanos é outra área que demonstra o acerto das políticas de admissão sensíveis à raça. Considerando o total de alunos que ingressaram nas 28 instituições seletivas investigadas, os negros se fizeram muito mais presentes que os brancos na liderança de organizações da sociedade civil, principalmente nos campos da assistência social, do trabalho com a juventude e do apoio à escola.

O livro mostra de forma incisiva que não existe, portanto, qualquer causalidade sociológica real entre as notas obtidas pelos alunos nos testes padronizados anteriores à graduação, as notas obtidas na própria universidade e o "sucesso" após o final desta. 
De fato, as realizações educacionais e profissionais posteriores e a satisfação com a graduação, no caso dos alunos negros, foi tanto maior quanto mais seletiva era a instituição freqüentada, o que demonstra, sem muita brecha para dúvidas, que os negros admitidos nessas instituições aproveitaram integralmente as oportunidades educacionais a que tiveram acesso e não foram, portanto, impactados por possíveis efeitos desmoralizantes oriundos do fato de que obtiveram pontuações anteriores, em geral menores que as dos brancos.

Por outro lado, os autores mostram que, se existiu algum ônus para os negros, por aceitarem uma forma "privilegiada" de acesso aos bancos do ensino superior, esse ônus parece ter sido largamente superado pelos resultados que os estudantes obtiveram para suas vidas individuais.

Um elemento fundamental no trabalho realizado por Bowen e Bok diz respeito à forma como os alunos negros e brancos investigados apontam como muito positiva a oportunidade de convivência cotidiana com indivíduos de raças diferentes, o que viabiliza o crescimento da compreensão recíproca no sentido de garantir configurações ótimas de vida e trabalho em conjunto.

O estudo lembra ainda que, após três décadas de prática contínua da “admissão sensível à raça", não houve retrocesso nas relações entre brancos e negros ou um acirramento de conflitos raciais. Ao contrário disto, segundo os autores, os brancos norte-americanos nesse período desenvolveram uma maior sistematicidade no respeito à população negra, embora o país esteja ainda muito longe de ser um paraíso de igualdade racial.

Tudo isto acaba pondo em relevo a necessária discussão acerca do que significa a fugidia categoria de "mérito". O livro enfatiza que, se não existem meios absolutos para definição de quem merece ou não acessar uma instituição de ensino seletivo, utilizar somente notas e pontuações garante ainda menos que os selecionados são aqueles que poderão "fazer diferença” para a sociedade como um todo. Notas e pontuações anteriores expressam variáveis múltiplas, inclusive as características familiares e os colégios de origem, mas não são garantias de diferenças intrínsecas aos candidatos, capazes de os classificar como "merecedores" ou "não merecedores" de oportunidades educacionais.

Considerar a raça como um dos elementos para a definição do merecimento possibilita o alcance de três objetivos fundamentais das instituições de ensino superior. Em primeiro lugar, estaria a identificação de alunos com grande potencial. Em segundo, a otimização dos ganhos educativos relacionados 
com a diversidade no corpo discente. Em terceiro lugar, a possibilidade de formar indivíduos que vão atender às necessidades sociais mais amplas. Este último ponto é sempre enfatizado pelo estudo, ao lembrar que os alunos negros egressos de instituições de ensino superior mais seletivas se tornam em maior medida líderes em suas comunidades e em organizações da sociedade civil voltadas para as parcelas mais desprotegidas da população.

A seleção sensível à raça, portanto, traz ganhos qualitativos para a lógica da formação acadêmica, mas também segue na direção de uma meta social que deve ser válida para toda a sociedade: a igualdade racial. $\mathrm{O}$ alcance dessa meta demanda, entre outros elementos, a existência de diplomados negros com capacidade para ocupar postos de liderança em várias áreas de atuação, seja no setor público, no setor privado ou em organizações civis.

Concluindo, podemos afirmar que a leitura de $O$ Curso do Rio mostra imediatamente ao leitor brasileiro muitas semelhanças entre os argumentos contrários à consideração da raça para admissão no ensino superior esgrimidos nos Estados Unidos e aqui. No entanto, parece-nos que tem grande relevância a ausência absoluta no debate nacional de um ponto fundamental na justificativa de Bowen e Bok para a existência de tal política: a incorporação dos negros às instituições de grande qualidade seria importante não somente para esse grupo, mas também para o conjunto da sociedade.

Trata-se, aqui, da valorização da diversidade, que é caracterizada como a possibilidade de convivência e interação construtiva e não-hierarquizada entre "indivíduos dessemelhantes". Na visão dos autores, a diversidade traz benefícios educacionais para as instituições de ensino, ao potencializar a reflexão acadêmica no campus e para a sociedade em geral, ao produzir um estoque mais amplo de indivíduos talentosos capazes de exercer funções importantes na vida local ou nacional.

Talvez, ao fim do livro, tenhamos que nos perguntar: por que essa linha de argumentação se faz ausente mesmo entre os mais arraigados defensores tupiniquins da política de cotas para negros no ensino superior? 


\section{NOTAS}

* Professor da Escola de Serviço Social da Universidade Federal Fluminense; pesquisador do Programa de Educação Sobre o Negro na Sociedade Brasileira (PENESB-UFF); Doutor em Ciências Sociais. Endereço eletrônico: aapbuff@ hotmail.com.

** Graduanda da Escola de Serviço Social da Universidade Federal Fluminense; bolsista do CNPq. 